\title{
Microinjection into zebrafish embryos (Danio rerio) - a useful tool in aquatic toxicity testing?
}

Sophia Schubert, Nadia Keddig, Reinhold Hanel and Ulrike Kammann

\begin{abstract}
Background: Microinjection was tested as a potentially powerful tool to introduce natural and anthropogenic pollutants directly into fish eggs to determine their toxicological impact on fish. With this technique, parental transfer of lipophilic contaminants may be mimicked. Here, we investigated the applicability of pollutant injection into the yolk of early zebrafish (Danio rerio) eggs with special regard on survival after vehicle injection. Tested vehicles were autoclaved tap water, dimethyl sulfoxide (DMSO), methanol, and triolein.
\end{abstract}

Results: Highest mortality occurred after the injection of DMSO and methanol. The lethality rates were up to 40\% higher than under control conditions. Best survival rates were obtained after triolein and water injections. However, the triolein droplet was not assimilated by the embryo within $96 \mathrm{~h}$ post fertilization suggesting an incomplete uptake of triolein-solubilized chemicals. Technical aspects concerning microinjection in zebrafish eggs are discussed with special emphasis on quantitative injection.

Conclusions: Microinjection into the yolk cell of zebrafish eggs is feasible, but the application of exact volumes appears problematic. However, microinjection is a powerful tool for studies without the demand for high volume accuracy. Adopting microinjection for pollutant research requires further investigation.

Keywords: Toxicity testing; Microinjection; Zebrafish embryo; Vehicle injection; Triolein; Dimethyl sulfoxide; Methanol

\section{Background}

Early life stages often show a greater sensitivity towards contaminants than adults $[1,2]$. Hence, for environmental risk assessment, it is specifically important to determine the influence of contaminants during embryonic development. Early life stages of aquatic species including fish face different pollutant exposure routes. Besides maternal transfer, in which contaminants are mobilized during game to genesis together with parental fat reserves to build up ovaries [3-5], they experience waterborne exposure or get in direct contact to the sediment, immediately after the embryo is released into the environment.

In wild fish, significant pollutant concentrations have been found in both, oocytes $[3,6]$ and spawned eggs $[1,7]$ giving evidence that maternal pollutant transfer in fish

\footnotetext{
* Correspondence: sos-publication@gmx.net

Institute of Fisheries Ecology, Thünen Institute (TI), Palmaille 9, 22767 Hamburg, Germany
}

cannot be neglected. The pollutant transfer from adults to offspring was also investigated in laboratory studies with medaka [5] and zebrafish [8,9]. In these studies, fish were exposed to pollutants and observed for several weeks. A potent way to mimic maternal pollutant transfer with the advantage to shorten the experimental duration offers the direct substance administration into the early fish egg via microinjection.

During the last decades, microinjection has been widely used in experimental biology. Microinjection allows, e.g., the production of transgenic cell lines or animals. It also offers the direct administration of supporting or harmful substances into cells to investigate their mode of action or toxic potential $[10,11]$. Unlike the classical Fish Embryo Toxicity Test, both polar and nonpolar substances can be administered and natural barriers, i.e., the chorion [12] and embryonic envelope, can be overcome. However, microinjection as a tool for the administration of contaminants has only rarely been tested. In the early

\section{Springer}


1990s, xenobiotics [13] and different organochlorines [14-16] were injected into rainbow trout eggs. This studies resulted in relatively high mortalities even for the control groups $(\geq 30 \%)$ questioning the reliability of the method [17-19]. Since the year 2000, Japanese medaka became the most favorable species for toxicant application via microinjection [20-28].

Medaka is a common model organism for many laboratory purposes. It is easy to maintain, comprise a fast development, and its embryos are moderately transparent and therefore an adequate choice for developmental studies [17]. The yolk of medaka embryos has additional oil droplets comprising lipid reserves necessary as nutritional resources during development $[10,11,29,30]$. Prior to injection, pollutants were diluted into triolein to mimic one of the natural oil droplets. Other fish species were rarely tested in microinjection studies linked to toxicity evaluation so far. However, investigating the effects of injected toxicants to species other then medaka is important to develop more generalized toxicity levels.

Even though $D$. rerio is a common vertebrate model, it was so far not used for direct pollutant administration directly into the egg yolk to mimic maternal transfer. Due to the phylogenetic divergence of medaka and zebrafish, a comparative approach seems appropriate to test, whether the injection procedure itself is equally harmless to the embryos of zebrafish as compared to medaka. Thereby, we aim for basic parameters that are essential for a reliable microinjection procedure into the yolk cell of one-cell staged zebrafish embryos.

In a second step, we tested the effect of four different vehicle substances, i.e., water, dimethyl sulfoxide (DMSO), methanol, and triolein on zebrafish embryos. Water, DMSO, and methanol are regularly used as solvents in bioassays like the Fish Embryo Toxicity (FET) Test. Salts, alcohols, and acids are easily solved in water. Methanol is often used to extract other polar substances as secondary metabolites of plants and other biomaterials [31]. DMSO is known to improve the solubility of less polar contaminants and is accepted not to be harmful to the developing individuals as long as their concentrations were kept below $2.5 \% \mathrm{v} / \mathrm{v}$ in the FET [31]. In contrast, triolein is presumably an excellent carrier for lipophilic substances. It was found to be the most promising vehicle administered in medaka embryos causing a very low mortality among them. Identifying a variety of vehicle substances offering the possibility to administer a wide range of polar and nonpolar substances directly into the yolk of eggs with one-cell staged zebrafish embryo is one major aim of our study. This will add basic knowledge to the field of environmental toxicity testing.

\section{Results}

The survival after vehicle injection ranged from $100 \%$ to $60 \%$ depending on the injected substance as well as the injection volume within $24 \mathrm{~h}$ post fertilization (hpf). Between 24 and $96 \mathrm{hpf}$, survival of injected embryos decreased not significantly (Table 1 ). Individuals injected with $4.2 \mathrm{~nL}$ DMSO or methanol showed significantly lower survival rates than zebrafish eggs after injection with similar volumes of autoclaved tap water or triolein (Figure 1A, B, Table 2). In general, the strength of an effect depends on injection volumes. Smaller injection volumes caused comparably less, but not significantly less mortality.

A DMSO injection of $0.5 \mathrm{~nL}$ resulted in $12 \%$ mortality $24 \mathrm{hpf}$. All other vehicle substances caused less mortality. However, high visible volume alterations occurred especially during DMSO and methanol injections. No secure statement of the real volume in place of the nominal volume can be made especially for methanol. Highest volume constancy was obtained after triolein injection. A distinct oil droplet appeared in the yolk sac, which was still visible 96 hpf (Figure 2).

\section{Discussion}

The experiments show that the microinjection of substances into the yolk of early egg stages of the zebrafish

Table 1 Survival rates (SR) of zebrafish (Danio rerio) eggs after vehicle injection

\begin{tabular}{|c|c|c|c|c|c|c|c|}
\hline Substance & Eggs & Replicates & Volume [nL] & 24 h SR [\%] & SD & 96 h SR [\%] & SD \\
\hline Untreated & 718 & 6 & - & 100 & 0 & 98 & 3.6 \\
\hline \multirow{2}{*}{ Autoclaved water } & 121 & 3 & 0.5 & 100 & 0 & 95 & 0 \\
\hline & 155 & 3 & 4.2 & 84 & 2.9 & 84 & 2.9 \\
\hline \multirow{2}{*}{ DMSO } & 158 & 3 & 0.5 & 88 & 5.9 & 88 & 8.7 \\
\hline & 90 & 3 & 4.2 & 60 & 5.0 & 55 & 6.2 \\
\hline \multirow{2}{*}{ Methanol } & 125 & 3 & 0.5 & 97 & 0.9 & 96 & 1.6 \\
\hline & 92 & 4 & 4.2 & 63 & 10.8 & 59 & 9.9 \\
\hline \multirow{2}{*}{ Triolein } & 94 & 3 & 0.5 & 97 & 2.4 & 96 & 0.4 \\
\hline & 110 & 3 & 4.2 & 94 & 3.5 & 94 & 3.5 \\
\hline
\end{tabular}

Untreated (pooled data) and after the pure injection of autoclaved tap water, DMSO, methanol, and triolein 24 and $96 \mathrm{~h}$ post fertilization (hpf), given with standard deviation (SD), respectively, total number of injected eggs, number of replicates, and injection volumes. 

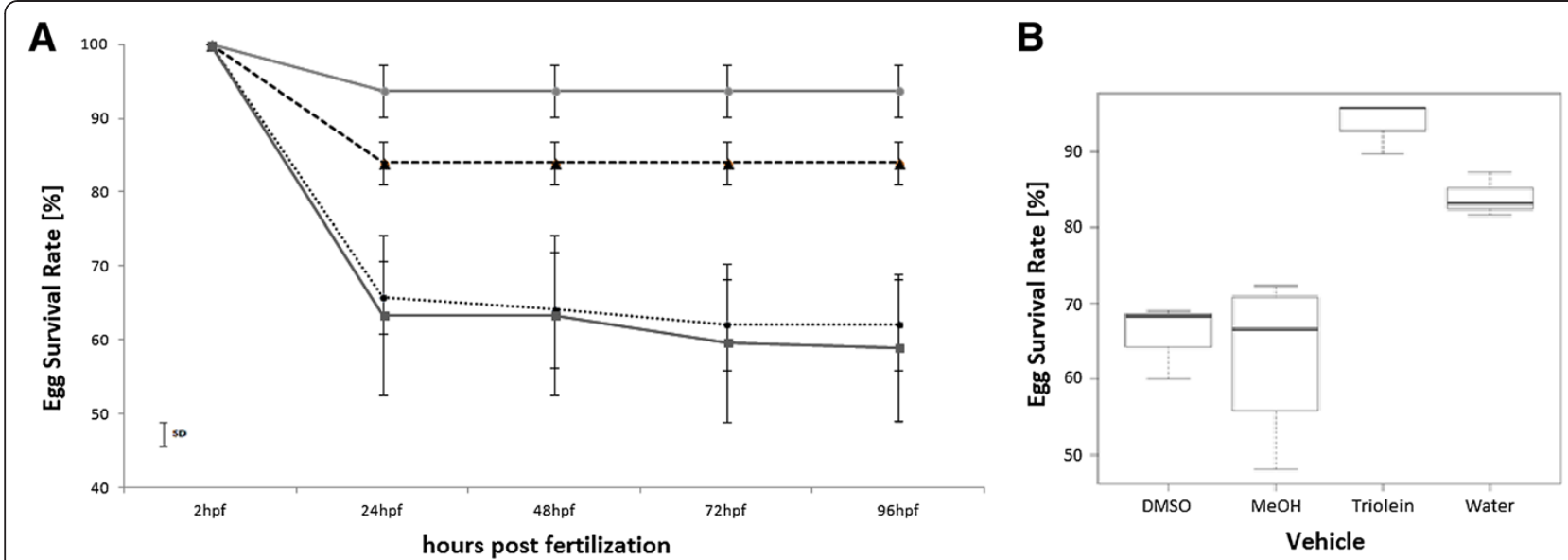

Figure 1 Survival rates of zebrafish eggs after vehicle injection and $24 \mathrm{~h}$ post injection with $4.2 \mathrm{~nL}$ vehicle. (A) Survival rates [\%] of zebrafish eggs after vehicle injection into the yolk sac of the one-cell stages ( $V=4.2 \mathrm{~nL}$, respectively) differed depending on substance: highest

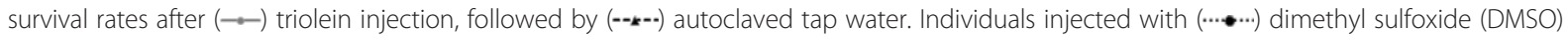
or ( --$)$ methanol showed lower survival rates. (SD = standard deviation). (B) Survival rates of zebrafish eggs $24 \mathrm{~h}$ post injection with $4.2 \mathrm{~nL}$ vehicle, respectively, showing differences in survival. Highest survival rates were obtained after triolein injection, followed by water, DMSO, and methanol $(\mathrm{MeOH})$ injection.

embryo is a feasible tool even though survival rates differ depending on the injected vehicle. Methanol and DMSO caused higher mortalities after injection into egg yolk than triolein or water. From this result, DMSO and methanol cannot be recommended as putative vehicles for microinjection into the yolk of one- to two-cell staged zebrafish eggs. The high mortality rate after DMSO injection matches previous results for rainbow trout (Oncorhynchus mykiss) eggs [15,16]. For O. mykiss mortality rates after the injection of DMSO, acetone, and dioxane were found to be higher than $60 \%$. Even though dosedependent survival rates could be shown, the high mortalities in the control groups challenged the reliability of the method [17-19].

Triolein was chosen for the application of lipophilic substances to mimic a maternal pollutant transfer. It has already been successfully used for microinjection into early egg stages of medaka (Oryzias latipes) carrying ciguatoxin $[21,25]$, type B brevetoxin [24], and azaspiracid-1 [19] as well as anthropogenic substances as tributyltin [26], a DDT metabolite [23], pharmaceuticals [28], crude oil extracts [26], and polychlorinated naphthalenes [22]. In

Table 2 Pairwise comparison of survival rates of zebrafish eggs $24 \mathrm{~h}$ after vehicle injection

\begin{tabular}{llll}
\hline & DMSO & MeOH & Triolein \\
\hline MeOH & 0.65795 & - & - \\
Triolein & $0.00084^{*}$ & $0.00029^{*}$ & - \\
Water & $0.01097^{* *}$ & $0.00379^{*}$ & 0.12088
\end{tabular}

One-cell staged eggs were injected with $4.2 \mathrm{~nL}$ of either dimethyl sulfoxide (DMSO), methanol (MeOH), autoclaved tap water, or triolein. Differences between survival rates were *significant after Bonferroni correction $(p \leq 0.008)$ and ${ }^{* *}$ significant without Bonferroni correction $(p \leq 0.05)$. contrast to zebrafish embryos, eggs of medaka naturally contain oil droplets which are involved in embryo developmental processes $[10,11,29,30]$. Mortality rates in vehicle controls tend to zero after the pure injection of triolein [20-28]. Our results concerning low mortalities post oil injection into the embryos of $D$. rerio are in accordance with the results for medaka. However, triolein was not assimilated by the zebrafish embryo until the termination of the experiment 96 hpf. We assume that a lipophilic pollutant dissolved in such a triolein droplet will not substantially affect the development of a zebrafish embryo during this time. It may be possible that an injected triolein droplet is assimilated later than $96 \mathrm{hpf}$, as zebrafish embryos completely consume their yolk sac during $165 \pm$ $12 \mathrm{hpf}$ [32]. To clarify whether the injected oil droplet is generally assimilated at a later point in development of zebrafish embryos, a prolongation of the experiment may be considered. However, in this case, the whole experiment needs permission by the Animal Welfare Act which would be contradictory to the general idea of the microinjection to be an alternative to experiments with adult animals concerning maternal transfer.

Water could be shown to be an adequate vehicle causing mortalities below $20 \%$ in zebrafish embryos when low volumes were injected $(\leq 4.2 \mathrm{~nL})$. The injection volume seems to be an important factor for egg survival post injection. High injection volumes $(\geq 4.2 \mathrm{~nL})$ cause yolk sac swelling. Consequently, yolk sac content leaks through the injection piercing if it is not sealed. Survival rates can be enhanced by $14 \%$ by sealing immediately after vehicle injection as has been shown for salmonid eggs [15]. However, sealing of any injection hole is a time consuming procedure. Instead of sealing, we decided to 

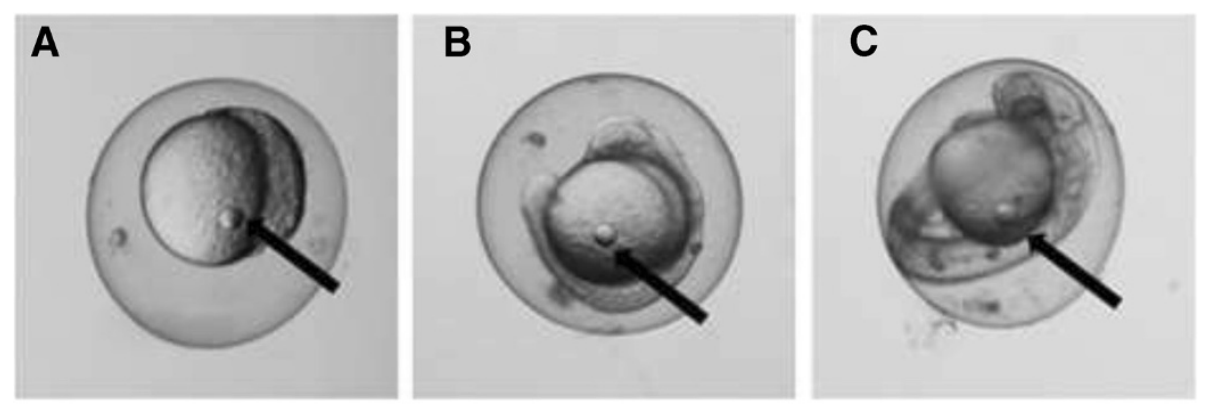

Figure 2 Developmental stages of a zebrafish embryo after injection of $4.2 \mathrm{~nL}$ triolein into the one-cell stage. Injected triolein droplet remains visible inside the yolk sac at (A) 2 hpf, (B) 24 hpf, and (C) 48 hpf.

use small injection volumes. The chosen volume of $4.2 \mathrm{~nL}$ does not exceed $10 \%$ of zebrafish egg volume, which was recommended to avoid egg trauma by Walker et al. [15]. In our experiments, no yolk sac leaking post egg injection was observed after the injection of $4.2 \mathrm{~nL}$.

Survival of triolein-injected individuals showed no remarkable difference between the tested injection volumes. For water, methanol, and DMSO, we found higher survival rates for smaller injection volumes. In general, the injection volume is directly linked to the applied concentration. An increase in volume resulted in a simultaneous increase in dose. However, this is only true for methanol and DMSO, which are known to be toxic to the fish embryo in higher concentrations [31], but cannot be assumed for water. Water is generally nontoxic to the fish embryo. Hence, smaller injection volumes seem to cause less mortality [14]. However, a smaller injection volume needs less injection pressure and/or a shorter injection time, which appears advantageous at the first sight. But the risk of needle clogging is enhanced at the same time. Volume constancy over a series of injections may therefore not be warranted when low volumes are injected. We observed this effect especially during the injection of low methanol volumes. The injection needle was successively clogging, and an injection droplet was not always visible. Hence, the high survival rate after the injection of $0.5 \mathrm{~nL}$ methanol is possibly overestimated. Methanol as a putative vehicle was not tested before in any of the prior studies concerning microinjection as tool for pollutant administration. However, it is used in a few cases as substance carrier for, e.g., perfluorooctane sulfonate (PFOS) [33] and was shown to be tolerated up to a concentration of $2 \%$ by early zebrafish embryos in the Fish Embryo Toxicity Test [31].

Generally, volume fluctuations may be due to changes on needle tip diameters or depend on the viscosity of the cytoplasm of the injected cell [34]. During the experiments, volume variations appeared on a regular basis. As these volume differences result in concentration shifts, the nominal and the real concentrations differ from each other by an unknown dimension. In ecotoxicology, high-quality data are essential and concentration variation as a consequence of volume oscillations affect data reliability. According to the OECD guideline for the Fish Embryo Toxicity Test, nominal and real concentrations should not differ more than $\pm 20 \%$ from each other to assure data reliability [18]. As volume variations occur regularly and partly unnoticed throughout a series of injections, it is not warranted that the real concentration deviates maximal $\pm 20 \%$ from the nominal concentration. Hence, the use of data derived from microinjection is presumably not feasible for the risk assessment of pollutants.

Furthermore, volume determination in general is difficult as injection volumes are in pico- to nanoliter range. Here, an object micrometer was used for the volume identification. Depending on the micrometer scale, volume determination is more or less accurate. It comprises a high-error risk. Differences in droplet diameter of $10 \mu \mathrm{m}$ lead to approximately $10 \%$ differences in calculated injection volumes. To further reduce the higherror risk, it may be reasonable to use a micrometer with an even smaller scale. Due to the rapid development of a zebrafish egg [35] and therefore for time saving as well as practical reasons, we determined the injection volume prior and past a series of 40 to 60 injections of one vehicle in a droplet of mineral oil spotted on the micrometer scale [36]. Hence, volume oscillations between single injections were not observed. Probably the best way to circumvent this effect is to measure the diameter of the injected droplet inside the egg. But this is not feasible for any vehicle. A distinct injection droplet in the shape of a sphere was only visible after triolein administration. The droplets appearing after DMSO, methanol, or water injection were rather diffuse. They had either no distinct shape or appeared as several small injection droplets within the yolk. Volume determination after each injection was not feasible in any of the described scenarios.

Diameters of injected triolein have previously been determined for medaka. Due to the volume oscillations between single injections, the authors reported a volume 
range instead of a distinct injection volume for dose-response relationships [25,37]. Nominal and real concentrations are not identical for any single injection. As mentioned above, this approach may lead to uncertain data not feasible for any effect concentration (EC) calculation or to estimate the risk potency of a pollutant.

\section{Recommendations for the use of microinjections as tool in toxicity testing}

In general, toxicity studies with fish eggs require a sufficient number of healthy and freshly fertilized eggs for each concentration and control treatment to assure the gain of reliable dose-response relationships of the tested contaminant. Therefore, the use of laboratory fish as, e.g., zebrafish or medaka has the major advantage of constant egg supply throughout the year independent from seasons and environmental disturbances. In general, for zebrafish two spawning routes are established within different laboratories. These are mass and group spawning [17,18,38]. During mass spawning, relatively high numbers of eggs are produced once a day. Due to the rapid development of the zebrafish embryos [38,39] gaining a high number of eggs within a single egg stage is rather difficult and, therefore, laborious pre-selecting of egg stages may be necessary. Contrary, group spawning offers a smaller but constant egg supply throughout the day, when groups are assembled consecutively and small fish groups can spawn one after another $[17,18]$. Due to the rapid development of the zebrafish eggs and the demand to inject in at least similar egg stages to assure similar distribution patterns of the contaminant within the embryo, we advise to favor group spawning over mass spawning for further applications.

The use of laboratory fish assures a high value of reproducibility, even if a constant egg supply may experience variations in egg quality and quantity due to variations in the breed. To identify variations in egg quality, it is recommended to determine the spontaneous lethality rate of the fish breed. This rate is a measure for all mortality events putatively occurring during embryonic development without any influence of a harmful substance or microinjection. The spontaneous lethality rate is needed to keep tests reproducible and reliable throughout parallel and repeated tests, (KNK, SS, Wosniok W, submitted). It can be determined in short examinations prior to experiments. To distinguish already low contaminant effects from background mortality, we propose a correspondingly low spontaneous lethality rate $(\leq 2.5 \%)$, which is in line with the results from Kammann et al. [40,41]. In comparison, the OECD recommends to discard datasets with a lethality equal or above $10 \%$ under control conditions $[18,19]$. Ali et al. [42] found a spontaneous lethality for zebrafish ELS test to be 9\% in control treatments. Due to the purpose of a study, a small spontaneous lethality rate may be essential especially when the authors are aiming for EC10 instead of EC50. In this case, distinguishing a substance effect from the background mortality is more crucial, (KNK, SS, Wosniok W, submitted), [43].

We further recommend for $D$. rerio injecting substances during the earliest developmental stages. The most homogeneous distribution of injected substances throughout the addressed compartment was achieved by keeping track of a GFP protein distribution during the initial developmental stages, i.e., the one-cell stage (data not shown). This strategy offers another advantage. Piercing the chorion by an injection needle may become more difficult with ongoing development of fish eggs due to the chorion hardening $[44,45]$. It is recommended that injection needles should be mostly inflexible and sharp to pierce a chorion even though it is already hardening and to avoid unwanted egg or needle damage [46].

Besides, the usage of appropriate needles, a sufficient supply of healthy and fertilized eggs, as well as the determination of the spontaneous lethality rate, we recommend examining the success rate. It describes the number of times when the contaminant is successfully injected into the addressed compartment. However, we propose that the success rate should be above $90 \%$. Accepting a rate below this recommendation leads to the detection of either false-positive or even no results.

\section{Conclusions}

Microinjection is an easy way to administer substances into newly fertilized fish eggs comprising many advantages. Once established in the lab, it can be applied for many fish species with only minor modifications. Effects on embryonic development become visible almost immediately after injection. Even small contaminant effects can be distinguished from background mortality. In contrast to the classical Fish Embryo Toxicity Test, both polar and nonpolar substances can be administered and natural barriers, i.e., the chorion [12] and embryonic envelope, can be overcome. However, preventing volume oscillations across consecutive injections remain difficult. Therefore, the usage of microinjection as a tool for the calculation of dose-response relationships in terms of environmental risk assessment may be problematic.

\section{Methods}

\section{Maintenance and egg production of zebrafish}

Wild-type zebrafish brood stock was held in breeding groups of about 20 females and 30 males in the facilities of the Thünen Institute of Fisheries Ecology in Hamburg, Germany. Fish were kept in three glass aquaria $(160 \mathrm{~L})$ at $26^{\circ} \mathrm{C} \pm 2^{\circ} \mathrm{C}$ and a light/dark period of $14 \mathrm{~h} / 10 \mathrm{~h}$ in tap water. Water quality was maintained by external bioactive filter devices. Filter material and aquarium water were changed twice a week. Fish were fed ad libitum twice a 
day with dry flake food (Tetramin, Tetra Werke, Melle, Germany).

Embryos were obtained from mass spawning. Eggs were collected $30 \mathrm{~min}$ after the light was switched on and rinsed in aquarium water. Embryos were inspected under an inverted microscope and staged according to Kimmel et al. [47].

\section{Assurance of egg quality/validation criteria}

For valid experiments, eggs were obtained only from spawns with a fertilization rate higher than $70 \%$ according to the OECD guideline for fish-egg assays with zebrafish embryos [18]. Spontaneous lethality (SL) of the fish breed was determined on a regular basis and used as a measure of egg quality. In sterile 24-well plates, embryos were kept in groups of five eggs per well under standard test conditions without the influence of any toxicant for $96 \mathrm{~h}$. Each well contained $1 \mathrm{~mL}$ of autoclaved tap water. The plates were kept at $26^{\circ} \mathrm{C} \pm 2{ }^{\circ} \mathrm{C}$ and a light/dark period of $14 \mathrm{~h} / 10 \mathrm{~h}$. Dissolved oxygen was not measured as no severe oxygen stress for the embryo was expected during the test procedure. Braunbeck et al. [17] reported that zebrafish eggs are capable to tolerate oxygen concentrations of $2 \mathrm{mg} / \mathrm{L}$ without the development of malformations. Furthermore, even $100 \mu \mathrm{L}$ water per egg was tested indicating no appearing oxygen stress. Here, the used water volume per egg was at least $200 \mu \mathrm{L}$.

In three independent tests, each with 120 zebrafish eggs, mean SL was determined. Additionally, each microinjection test comprised a negative control containing 60 eggs, which were neither treated with any pollutant nor subjected to the microinjection procedure itself. In general, for valid test procedures the control group needed to have a survival rate higher than $90 \%[18,19]$.

\section{Chemicals and substances}

Injection vehicles were purchased and prepared as follows: methanol $(99,9 \%)$ was obtained from Merck KGaA, Darmstadt, Federal State of Hesse, Germany. Triolein $(\geq 99 \%)$ and DMSO (CHROMASOLV, 99.7\%) were purchased from Sigma-Aldrich, Seelze, Federal State of Lower Saxony, Germany. All substances were used undiluted. High-quality tap water $\left(\leq 8^{\circ} \mathrm{dH}\right)$ was autoclaved prior to experiments. Aliquots of vehicles were kept in the fridge at $4^{\circ} \mathrm{C}$ prior to experiments.

\section{Microinjection}

\section{Preparation}

Injection needles (needle types: O.D. $=20 \mu \mathrm{m}$; BM100T10, ends fire polished, beveled, Biomedical Instruments, Germany or Femtotip II, Eppendorf, Germany) were backfilled with $10 \mu \mathrm{L}$ substance by a Microloader (Eppendorf, Germany). The needle was placed in the microinjection manipulator (Narishige MN-151, Narishige International
Limited, London, United Kingdom) connected to a pneumatic microinjection pump (FemtoJet from Eppendorf, Germany). Injections were made with $\times 20$ magnification under an inverted microscope (Nikon MSZ800, Nikon GmbH, Düsseldorf, Federal State of North RhineWestphalia, Germany). Injection volume was determined according to Sive et al. [37] by an object micrometer (Bresser 1/10 mm, Bresser GmbH, Rhede, Federal State of North Rhine-Westphalia, Germany). Briefly, for the three vehicles, DMSO, methanol, and water, a mineral droplet was mounted on the scale of the object micrometer. For triolein, a drop of water was used as matrix for measurements. The arising vehicle sphere was measured with the scale of the object micrometer. Each vehicle was administered several times into the oil droplet until the target injection volume was achieved. According to the sphere volume formula $\left(V=1 / 6 \pi d^{3}\right)$, a sphere diameter of 1 bar corresponded to an injection volume of $0.5 \mathrm{~nL}$. Two bars corresponded to $4.2 \mathrm{~nL}$. Injection volume needed to be measured and adjusted for every solution, concentration as well as for every control prior and past injections due to the putative variations at the needle tip during injection procedure.

\section{Procedure}

One-cell stadium zebrafish embryos were stringed at the edge of a microscope slide placed in a petri dish. Surplus water was removed with a paper towel such that the eggs were immobilized during the injection procedure. Per treatment between 40 and 60 eggs was consistently injected with triolein, DMSO, methanol, or autoclaved water, into the yolk. Each treatment was tested in triplicate.

To avoid needle clogging by any of the injection substances, capillaries were cleaned at frequent intervals. Post injection eggs were rinsed with autoclaved tap water $\left(26^{\circ} \mathrm{C} \pm 2^{\circ} \mathrm{C}\right)$ into a petri dish. After $2 \mathrm{~h}$, viable eggs were separated from coagulated and/or non-fertilized eggs and transferred in groups of two to five individuals into the wells of a 24-well plate. Viable eggs were kept in $1 \mathrm{~mL}$ autoclaved tap water at $26^{\circ} \mathrm{C} \pm 2^{\circ} \mathrm{C}$ and a $14 \mathrm{~h} /$ $10 \mathrm{~h}$-light/dark rhythm. Eggs were checked for coagulation and malformation every $24 \mathrm{~h}$. Experimentation was terminated at latest $96 \mathrm{~h}$ post fertilization (hpf).

\section{Statistics}

Survival rates of 24 h-old zebrafish embryos injected with $4.2 \mathrm{~nL}$ of each vehicle were normally distributed ( $p$ value $=0.69)$. A Fligner-Killeen test of homogeneity of variances yielded not significant $(\mathrm{df}=3, p$ value $=0.50)$. As a consequence, we performed a one-way analysis of means not assuming equal variances. It ended up in a significant differences between treatment groups $(p$ value $=0.003$ ) To identify the location of these differences, we chose a pairwise $t$-test which was Bonferroni corrected $(p \leq 0.008)$. 
The entire statistic was performed with the freeware ' $R$ ' [48]. All data are represented as means \pm standard deviation (SD).

\author{
Abbreviations \\ ANOVA: analysis of variances; DDT: dichlorodiphenyltrichloroethane; \\ DMSO: dimethyl sulfoxide; EC: effect concentration; hpf: hours post \\ fertilization; $\mathrm{MeOH}$ : methanol; SD: standard deviation; SL: spontaneous \\ lethality; SR: survival rate; TCDD: 2,3,7,8-tetrachlorodibenzo-p-dioxin.
}

\section{Competing interests}

The authors declare that they have no competing interests.

\section{Authors' contributions}

SS has designed the study, assembled, analyzed, and interpreted the data and wrote the manuscript. NK has made substantial contributions to the conception and design of the study and has been involved in drafting the manuscript and revising it critically for important intellectual content. $\mathrm{RH}$ and UK have been involved in drafting the manuscript and revising it critically for important intellectual content. All authors read and approved the final manuscript.

\section{Acknowledgements}

The authors thank Manfred Trenk and Marc Willenberg for their skillful technical assistance as well as Malte Damerau, Wolfgang Gerwinski, Michael Haarich, Norbert Theobald, Jochen Trautner, and Werner Wosniok for their thematic support. This study was incorporated into 'MERIT-MSFD: Methods for detection and assessment of risks for the marine ecosystem due to toxic contaminants in relation to implementation of the European Marine Strategy Framework Directive'. It was supported by a grant (grant number 10017012) from the German Federal Ministry of Transport and Digital Infrastructure (BMVI) and the German Maritime and Hydrographic Agency (BSH).

Received: 9 September 2014 Accepted: 6 December 2014

Published online: 24 December 2014

\section{References}

1. Russell RW, Gobas FAPC, Haffner GD: Maternal transfer and in ovo exposure of organochlorines in oviparous organisms: a model and field verification. Environ Sci Technol 1999, 33(Suppl):1-15.

2. Hutchinson TH, Solbe J, Kloepper-Sams PJ: Analysis of the ECETOC aquatic toxicity (EAT) database III - comparative toxicity of chemical substances to different life stages of aquatic organisms. Chemosphere 1998, 36:129-142.

3. Serrano R, Blanes MA, López FJ: Maternal transfer of organochlorine compounds to oocytes in wild and farmed gilthead sea bream (Sparus aurata). Chemosphere 2008, 70:561-566.

4. Russell RW, Gobas FAPC, Haffner GD: Maternal transfer and in ovo exposure of organochlorines in oviparous organisms: a model and field verification. Environ Sci Technol 1999, 33:416-420.

5. Van de Merwe JP, Chan AKY, Lei ENY, Yau MS, Lam MHW, Wu RSS: Bioaccumulation and maternal transfer of PBDE 47 in the marine medaka (Oryzias melastigma) following dietary exposure. Aquat Toxicol 2011, 103:199-204

6. Von Westernhagen $\mathrm{H}$, Rosenthal H: Bioaccumulating substances and reproductive success in Baltic flounder Platichthys flesus. Aquat Toxicol 1981, 1:85-99.

7. Peng H, Wei Q, Wan Y, Giesy JP, Li L, Hu J: Tissue distribution and maternal transfer of poly- and perfluorinated compounds in Chinese sturgeon (Acipenser sinensis): implications for reproductive risk. Environ Sci Technol 2010, 44:1868-1874.

8. Nyholm JR, Norman A, Norrgren L, Haglund P, Andersson PL: Maternal transfer of brominated flame retardants in zebrafish (Danio rerio). Chemosphere 2008, 73:203-208.

9. King Heiden TC, Struble CA, Rise ML, Hessner MJ, Hutz RJ, Carvan MJ III: Molecular targets of 2,3,7,8-tetrachlorodibenzo-p-dioxin (TCDD) within the zebrafish ovary: insights into TCDD-induced endocrine disruption and reproductive toxicity. Reprod Toxicol 2008, 25:47-57.

10. Dodd A, Curtis PM, Williams LC, Love DR: Zebrafish: bridging the gap between development and disease. Hum Mol Genet 2000, 9:2443-2449.
11. Spitsbergen J, Kent M: The state of the art of the zebrafish model for toxicology and toxicologic pathology research - advantages and current limitations. Toxicol Pathol 2003, 31:62-87.

12. Mizell M, Romig ES: The aquatic vertebrate embryo as a sentinel for toxins: zebrafish embryo dechorionation and perivitelline space microinjection. Int J Dev Biol 1997, 41:411-423.

13. Norrgren L, Andersson T, Björk M: Liver morphology and cytochrome P450 activity in fry of rainbow trout after microinjection of lipid-soluble xenobiotics in the yolk-sac embryos. Aquat Toxicol 1993, 26:307-316.

14. Zabel E, Cook P, Peterson R: Toxic equivalency factors of polychlorinated dibenzo-p-dioxin, dibenzofuran and biphenyl congeners based on early life stage mortality in rainbow trout (Onchorhynchus mykiss). Aquat Toxicol 1995, 31:315-328.

15. Walker MK, Hufnagle LCJ, Clayton MK, Peterson RE: An egg injection method for assessing early life stage mortality of polychlorinated dibenzo-p-dioxins, dibenzofurans, and biphenyls in rainbow trout, (Onchorhynchus mykiss). Aquat Toxicol 1992, 22:15-38.

16. Walker MK, Spitsbergen JM, Olson JR, Peterson RE: 2, 3, 7, 8Tetrachlorodibenzo-p-dioxin (TCDD) toxicity during early life stage development of lake trout (Salvelinus namaycush). Can J Fish Aquat Sci 1991, 48:875-883.

17. Braunbeck T, Boettcher M, Hollert H, Kosmehl T, Lammer E, Leist E, Rudolf $M$, Seitz N: Towards an alternative for the acute fish $L C(50)$ test in chemical assessment: the fish embryo toxicity test goes multi-species an update. ALTEX 2005, 22:87-102.

18. OECD: Fish Embryo Acute Toxicity (FET) Test. Test Guideline No. 236. OECD Guidelines for the Testing of Chemicals. Paris: OECD Publishing; 2013:1-22. [OECD Guidelines for the Testing of Chemicals, Section 2]. www.oecd.org.

19. ASTM E729-96: Standard Guide for Conducting Acute Toxicity Tests on Test Materials with Fishes, Macroinvertebrates, and Amphibians. West Conshohocken, PA, United States: ASTM International; 2007:1-22. www.astm.org.

20. Colman JR, Twiner MJ, Hess P, McMahon T, Satake M, Yasumoto T, Doucette GJ, Ramsdell JS: Teratogenic effects of azaspiracid-1 identified by microinjection of Japanese medaka (Oryzias latipes) embryos. Toxicon 2005, 45:881-890.

21. Edmunds JS, McCarthy RA, Ramsdell JS: Ciguatoxin reduces larval survivability in finfish. Toxicon 1999, 37:1827-1832.

22. Villalobos SA, Papoulias DM, Meadows J, Blankenship AL, Pastva SD, Kannan $\mathrm{K}$, Hinton DE, Tillitt DE, Giesy JP: Toxic responses of medaka, d-rR strain, to polychlorinated naphthalene mixtures after embryonic exposure by in ovo nanoinjection: a partial life-cycle assessment. Environ Toxicol Chem 2000, 19:432-440.

23. Villalobos SA, Papoulias DM, Pastva SD, Blankenship AL, Maedows J, Tillit DE, Giesy JP: Toxicity of o, $p^{\prime}$-DDE to medaka d-rR strain after a one-time embryonic exposure by in ovo nanoinjection: an early through juvenile life cycle assessment. Chemosphere 2003, 53:819-826.

24. Colman JR, Ramsdell JS: The type B brevetoxin (PbTx-3) adversely affects development, cardiovascular function, and survival in medaka (Oryzias latipes) embryos. Environ Health Perspect 2003, 111:1920-1925.

25. Colman JR, Dechraoui M-YB, Dickey RW, Ramsdell JS: Characterization of the developmental toxicity of Caribbean ciguatoxins in finfish embryos. Toxicon 2004, 44:59-66.

26. Escoffier N, Gaudin J, Mezhoud K, Huet H, Chateau-Joubert S, Turquet J, Crespeau F, Edery M: Toxicity to medaka fish embryo development of okadaic acid and crude extracts of Prorocentrum dinoflagellates. Toxicon 2007, 49:1182-1192.

27. Hano T, Oshima Y, Kim SG, Satone H, Oba Y, Kitano T, Inoue S, Shimasaki $Y$, Honjo T: Tributyltin causes abnormal development in embryos of medaka, Oryzias latipes. Chemosphere 2007, 69:927-933.

28. Nassef M, Kim SG, Seki M, Kang IJ, Hano T, Shimasaki Y, Oshima Y: In ovo nanoinjection of triclosan, diclofenac and carbamazepine affects embryonic development of medaka fish (Oryzias latipes). Chemosphere 2010, 79:966-973.

29. Gonzalez-Doncel M, Okihiro MS, Villalobos SA, Hinton DE, Tarazona JV: A quick reference guide to the normal development of Oryzias latipes (Teleostei, Adrianichthyidae). J Appl Ichthyol 2005, 21:39-52.

30. Iwamatsu T: Stages of normal development in the medaka Oryzias latipes. Mech Dev 2004, 121:605-618.

31. Maes J, Verlooy L, Buenafe OE, de Witte PAM, Esguerra CV, Crawford AD: Evaluation of 14 organic solvents and carriers for screening applications in zebrafish embryos and larvae. PLoS One 2012, 7:e43850. 
32. Jardine D, Litvak MK: Direct yolk sac volume manipulation of zebrafish embryos and the relationship between offspring size and yolk sac volume. J Fish Biol 2003, 63:388-397.

33. Sharpe RL, Benskin JP, Laarman AH, Macleod SL, Martin JW, Wong CS, Goss GG: Perfluorooctane sulfonate toxicity, isomer-specific accumulation, and maternal transfer in zebrafish (Danio rerio) and rainbow trout (Oncorhynchus mykiss). Environ Toxicol Chem 2010, 29:1957-1966.

34. Minaschek G, Bereiter-Hahn J, Bertholdt G: Quantitation of the volume of liquid injected into cells by means of pressure. Exp Cell Res 1989, 183:434-442.

35. Kimmel CB, Law RD: Cell lineage of zebrafish blastomeres. Dev Biol 1985, 108:86-93.

36. Sive $H$, Grainger R, Harland R: Calibration of the injection volume for microinjection of Xenopus oocytes and embryos. Cold Spring Harb Protoc 2010, 2010:1382-1383.

37. Edmunds JS, McCarthy RA, Ramsdell JS: Permanent and functional maleto-female sex reversal in d-rR strain medaka (Oryzias latipes) following egg microinjection of o, p'-DDT. Environ Health Perspect 2000, 108:219-224.

38. M W: The Zebrafish Book. A Guide for the Laboratory Use of Zebrafish (Danio Rerio). 4th edition. Eugene: Univ. of Oregon Press; 2000.

39. Kimmel CB, Spray DC, Bennett MV: Developmental uncoupling between blastoderm and yolk cell in the embryo of the teleost Fundulus. Dev Biol 1984, 102:483-487.

40. Kammann $U$, Vobach M, Wosniok W: Toxic effects of brominated indoles and phenols on zebrafish embryos. Arch Environ Contam Toxicol 2006, 51:97-102.

41. Kammann U, Vobach M, Wosniok W, Schäffer A, Telscher A: Acute toxicity of 353-nonylphenol and its metabolites for zebrafish embryos. Environ Sci Pollut Res Int 2009, 16:227-231.

42. Ali S, van Mil HGJ, Richardson MK: Large-scale assessment of the zebrafish embryo as a possible predictive model in toxicity testing. PLoS One 2011, 6:e21076.

43. Scholz S, Fischer S, Gündel U, Küster E, Luckenbach T, Voelker D: The zebrafish embryo model in environmental risk assessment - applications beyond acute toxicity testing. Environ Sci Pollut Res Int 2008, 15:394-404.

44. Henn K, Braunbeck T: Dechorionation as a tool to improve the fish embryo toxicity test (FET) with the zebrafish (Danio rerio). Comp Biochem Physiol C Toxicol Pharmacol 2011, 153:91-98.

45. Robles V, Cabrita E, de Paz P, Herráez MP: Studies on chorion hardening inhibition and dechorionization in turbot embryos. Aquaculture 2007, 262:535-540.

46. Pase L, Lieschke GJ: Validating microRNA target transcripts using zebrafish Assays. Methods Mol Biol 2009, 546:227-240.

47. Kimmel CB, Ballard WW, Kimmel SR, Ullmann B, Schilling TF: Stages of embryonic development of the zebrafish. Dev Dyn 1995, 203:253-310.

48. R Core Team. R: a language and environment for statistical computing. Vienna, Austria: R Foundation for Statistical Computing. 2013; www.R-project.org.

\section{Submit your manuscript to a SpringerOpen ${ }^{\circ}$ journal and benefit from:}

- Convenient online submission

- Rigorous peer review

- Immediate publication on acceptance

- Open access: articles freely available online

- High visibility within the field

- Retaining the copyright to your article 